\title{
18 Natural resources as common goods
}

\author{
Alexa K. Lutzenberger, Franziska Lichter, \\ and Sarah Holzgreve
}

\section{Introduction}

Soil, water, air and biodiversity (genetic diversity) are among the most essential sources of life. With the existence of humankind, fierce battles over natural resources started - and continue to exist today. Main drivers of the diverse conflicts are besides climate change, the ongoing economic growth, and the increasing population accompanied by rising consumption patterns. Achieving food-waterenergy-security and health, mitigating and adapting to climate change, protecting biodiversity and reduce greenhouse gas emissions, among others, are only a few of the thematic challenges for humanity according to intra- and intergenerational justice and types of ownership. Sustainable resource use and management, which provides a constant everlasting amount of ecosystem services, is only possible if humanity creates a new path away from the existing business as usual capitalism of exploitation and greed (Söllner 2014). Only if politicians, businessmen and civil society learn to treat their resources sustainably according to Brundtland 1987 ('Our Common Future') (Butlin 1989) and inter alia in correlation to the concept of strong sustainability by Ott and Döring (2004) can the survival of humanity can be assumed. The concept of commons might be a vital contribution to overcome unsustainable management and ownership of global resources.

Various approaches are available to derive the topic of resources as common goods. This diversity of approaches comes from various scientific fields and social aspects. From this diversity, however, very different approaches to common goods and justice/distributive justice can be formulated and also approaches to implementation can be found. Discussions and approaches from politics and science are assigned to the following groups, among others:

- Ecological

- Planetary boundaries

- Environmental impact

- Ecological-social

- Health

- Basic necessities of life 
- Social

- Brundlandt-Kommission - inter- and intragenerational justice

- $\quad$ Living and working conditions

- Cultural - philosophical

- Justice as a philosophical approach

- Social sustainability as a cultural idea

- Socio-economic

- $\quad$ Living and working conditions

- Availability of resources

- Income development, GNP

- Human resources

- Economical

- Benefits and costs/benefits etc.

- Economic growth

- Ecological-economical

- Green economy, and so on.

Until today no uniform definition of common goods exists, and terminological fuzziness is a scientific reality. Therefore, a key question is: In how far can natural resources be defined as humanity's common goods, and is a concept of common goods and its inherent part of commoning helpful in reducing resource extraction, and preserving existing resources for future generations? The aim is to identify how natural resources can be defined and assorted and, in a second step, how common goods can be derived from that definition and being identified as humanity's common goods.

\section{Definition of natural resources}

A resource in the economic sense means to carry out an action and is equated with the term capital. Furthermore, it can be divided into labour capital, physical capital and natural capital, the latter being the only natural resource (Reller et al. 2014). In terms of the geo- and sustainability sciences, natural resources are understood more broadly as all-natural capital used in the past or potentially usable including the environmental compartments water, air, and soil as well as energetic, mineral, and biotic resources as plants and animals (Reller et al. 2014). In the broadest sense, all ecosystem functions of earth and the solar system usable by humans or funding human well-being are included (Schütz \& Bringezu 2008; Reid 2005; Bleischwitz et al. 2009). According to this, the United Nations Environment Programme (UNEP) International Resources Panel lists water, land, energy, and materials such as minerals, 


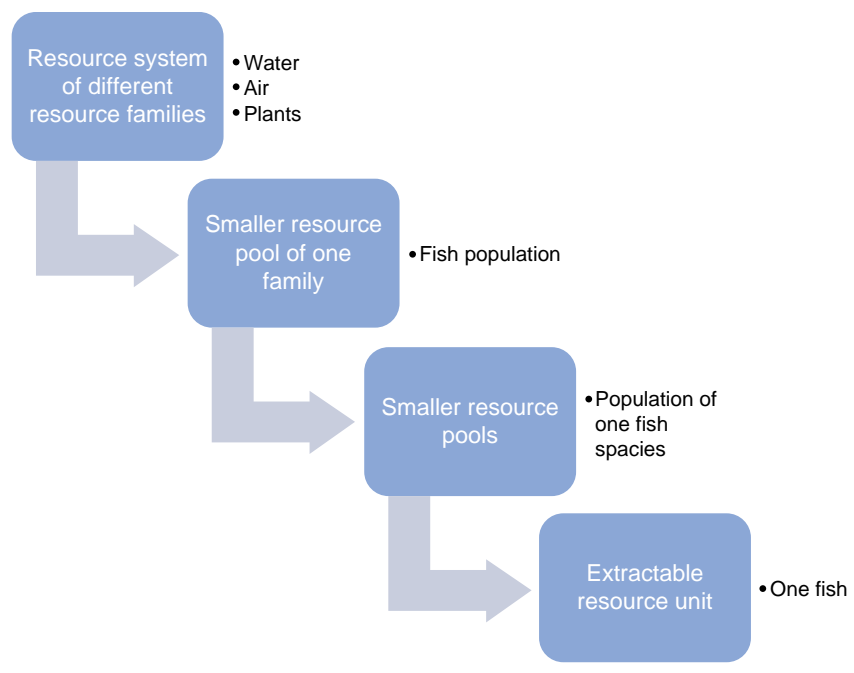

Figure 18.1 Scales of the resource system, pool and unit.

Source: based on Holzgreve (2015).

biomass and fossil fuels as natural resources (UNEP 2012). The German Resource Efficiency Programme (ProGress 2012) adds to the UNEP definition the biodiversity aspect and divides raw materials in abiotic materials like fossil fuels, ores, industrial minerals, and construction material; and material use, food/feedstuff and fuel as biotic material. The use of raw materials is herein closely connected with the use of other resources such as water, land/ soil, air, biological diversity and ecosystems (BMUB 2012).

Based on the mentioned definitions, natural resources can be defined broadly as the means for human actions and basis of human livelihoods provided by nature; namely the large-scale resource pools like water, air, soil/ land. They are extended by all ecosystem functions of earth and solar system usable by humans or funding human well-being (biodiversity, energy) and the extracted raw materials sub-categorised in biotic and abiotic materials. Their value for humanity - as resource pools embedded in ecosystems or as single resource units - is given by provisioning, supporting, cultural, and regulating ecosystem or resource services (Reid 2005). While local resource extraction reduces services to the provisioning and takes place at the local level, benefits from supporting and regulating services are of global significance.

\section{Definition of commons}

The classic economic view on different types of goods (cf. Chapter 1 on capital) is often used as a starting point in commons' discourses (Hardin 1968; de Moor 2011). Thus, goods are grouped normally into public goods, club goods, 
private goods, and common goods or rather common pool resources. Always depending on the degree of - access to, or exclusion from, as well as on the rivalry of use (scales from low to high) (de Moor 2011; Vanni 2014; Ostrom 1991). This economic classification (private, club, public) is based on forms of ownership, but in case of open access or common pool goods, there is no ownership according to an economic point of view. Furthermore, in classical economics, the Roman res nullius (no one's goods), and res communes (everyone's goods), have been merged into one category and considered to be at free disposal as underlined by Scott Gordon's sentence from 1954: 'Everybody's property is no-ones' property' (Gordon 1954). Differences between the types of collective ownership, public goods, and common goods are often blurred in the discourse on commons and make it necessary to define more clearly between them (Quilligan 2014).

Public goods are characterised by low excludability and a low rivalry of use. They are usually governed by the state to avoid free-riding. Public goods are generally subject to state-imposed regulations and laws on a large scale.

A common or common good in the classic sense refers according to present discourse to resources whose access and use intensity is managed jointly by negotiating rules against the background of traditions, norms, and practices (Quilligan 2014). It is a self-organised social system of assuming responsibility for renewable and finite, tangible (land, rivers) and less to intangible resources (atmosphere, internet) based on shared values and community identity with little link to market and state (Bollier 2014). Unlike a public good, it needs management and protection in order to endure (Hess 2008). Consequently, a common good starts to exist wherever and whenever a community decides to manage a resource collectively with particular attention to equal access, use and sustainability, and this is where the commoning process begins.

By upscaling from a common good unit like a single fish to common resource pools (fish species in one lake) to global commons (aggregated fish resource pools globally), the intersection with public goods is strongly increasing and raise the question to whom belongs the wind, atmosphere, fish etc. on a global level? As mentioned, a common pool resource consists of many single resource units which are used, mostly owned, and consumed by individuals. Therefore, a common pool resource, as well as a global common, is exploited by a large number of users in a relatively unrestricted and unregulated manner, making it more vulnerable to appropriation (de Moor 2011; Vanni 2014; Ostrom 1996) and due to lower access restrictions and usage regulation in comparison to private goods, prone to overuse and ultimately susceptible to the 'Tragedy of the Commons' mentioned by Hardin (1968). Regulatory forms and commoning are, therefore, regarded as particularly necessary for obtaining common pool resources and global commons (Hess 2008). Furthermore, both are characterised by the fact that they are classified according to economic tradition in the sector of free access and thus in the field of public goods. Therefore more participation rights and greater potential for co-determination 
are being demanded, as well as stronger regulation for the global commons. Forms of collective administration exist currently only to a small extent for them (de Moor 2011).

Subsequently, a common is here defined as: A system of resource governance consisting of a common pool resource which is compounded by single resource units (common good). The resource is addressed by an identifiable community of users, which initiate an identifiable process of commoning, where a shared aim in resource preservation and regulations for sustainable use, and governance of the relevant resource is discussed, adapted and installed. At least, as Silke Helfrich mentioned, everything can be a common (Helfrich 2012).

From the perspective of the Commons, it is, therefore, necessary to manage all-natural resources, without exception, at the local level according to their global significance as the common heritage of humanity - if we want to preserve them as the essential foundation of life on Earth for future generations.

\section{Development of a common good management concept}

Several innovative, regulatory strategies are established through a range of decision-makers, actors, partnerships and networks in a variety of formal and informal ways, including the collective action of common goods. This type of action is often associated with the term governance. According to Mayntz, in relation to the individual nation-state, governance means the totality of all the forms of collective regulation of social situations that exist side by side: 'from institutionalized civil society self-regulation through various forms of interaction between state and private actors, to the sovereign action of state actors' (Mayntz 2010).

In order to evaluate the diversity of ideas on the governance of common goods - concepts and management approach applied in abiotic and biotic common good areas - are filtered out. The underlying question is: What concepts and approaches can be considered successful in maintaining the productive use of common pool resources/common goods?

The identified concepts and approaches were checked for their independent transferability to other resources. The aim was to identify those concepts and approaches that have the potential to successfully manage other resources and to influence their management in a meaningful way. The inventoried concepts do not represent 'blueprints' in themselves. Their essential variables, which have contributed to successful management and collective action, were made visible. In addition, an overview has been given of the areas in which approaches exist and how they are structured. The focus of the study is on the period 1999-2014. This time span is at least necessary to understand the policy change related to sustainability, resource and climate change issues globally and regionally over the last decade. The resource sectors examined show that concrete research on concepts and approaches for the regulation and governance of common goods has been intensified in the last 15 years. The increasing complexity in the field of social interaction with natural resources, intensified by the increasing scarcity of 
resources, deterioration of living conditions or climatic changes of the last decades, call for new management approaches on all levels of action to be made visible. (1) During the data search, the entire intra-, inter- and transdisciplinary bandwidth was mapped as far as possible. (2) Ecological, economic, social, cultural and political constructs were taken into account in order to do justice to a sustainable understanding. (3) A further main focus was the identification of concepts and approaches in relation to the evaluated CG resources.

In total, 54 usable concepts were identified. All concepts were checked for six attributes. The first attribute, 'located organisational level', checks whether the concept is described at the formal or informal level (distinction at the macro level). The second attribute (collective choice arrangement) refers more precisely to the Community level. Namely, whether the concept is for example determined, regulated and developed by the community, by a social network with, for example, a cultural background (participation, micro-level). The third attribute (clearly defined biophysical boundaries) focuses on whether the biophysical boundaries of the considered common goods are defined. Biophysical properties are decisive: the occurrence, design and preservation of natural capital and influence ecosystem services. The fourth characteristic makes a distinction between common goods unit and common pool resource. It differentiates whether the focus of the concept is to be seen in the large-scale or small-scale perspective. The fifth property (transferability of the concept) assesses the transferability of the concept to other common good units and common pool resource. The last characteristic distinguishes seven categories: ecological, economic, social, cultural-philosophical.

In the category organisation level, most of the concepts (32) are designed at the formal level. This is essential for common goods, as formal management can secure the stability of resources through an organisational structure. Formal structures guarantee the safeguarding of decisions that have been taken or must be taken on the respective planning level (Zell 2011). The efficiency of the organisation of global and regional common goods can be enhanced by formal structures because more decisions can be made or more problems solved within a certain period of time.

Informal organisations include social structures in which interpersonal relationships play a major role (Zell 2011). Nine concepts could be identified with this feature. The aspect of social interaction is a major factor in the design of the commons according to the Institutional Framework for Policy Analysis and Design (IAD) (Polski \& Ostrom 1999). Potential for linking the formal and informal level for further developed concepts, which integrate the individual needs and ideas of informal organisation, could be found in 13 of the examined concepts.

In the category Common Good Entity or Common Pool Resource it could be analysed that most concepts (33) focus on common pool resources, nine on common goods units and 11 consider both. Overall, 36 of the 54 concepts analysed, offer a high transfer performance to other resources, with seven being located in the middle of transferability. 
It is clear from the document analysis that an interdisciplinary focus seems to be indispensable. Particularly with regard to global commons and common pool resources such as air, water, soil, etc., and especially with respect to the joint management of transboundary natural resources. Many of the biotic and abiotic resources are interrelated and build a common and continuously exchange. These complex contexts are not sufficiently taken into account in the examined approaches so far.

\section{Design principles for the assessment of management approaches}

The heuristic study of the management concepts and approaches is intended to address the question: Where and in which sectors are the strengths and weaknesses of the individual common pool resource/common good management concepts if they are reflected by minimum criteria in the design for a sustainable common pool resource/common good management? The referring sub-questions are:

a What management approaches promote a robust social-ecological system?

b Where the approaches are different from or similar to each other?

c Which approaches complement each other sensibly?

d And which approaches can be combined appropriately depending on the problem?

As a pioneer in the development of principles and criteria that promote sustainable common pool resource/common good management, Elinor Ostrom's work must be mentioned. By 1999, Ostrom had postulated eight principles, which she repeatedly evaluated over the years, and which have been tested, further developed, and supplemented in case studies by various authors (Anderies et al. 2004; Araral 2013; Bunch et al. 2011; Bruns 2008; Cox et al. 2010; Fowler 2003; Gruber 2010; Lindsay 1998; Ostrom 1999, 2008; Pomeroy et al. 1998; Stern 2011).

The aim was to create a matrix consisting of management approaches and evaluated design principles that could be evaluated in the form of a crossing scheme. The methodical procedure was divided into two main steps: First, the management approaches of the previously evaluated case studies were elevated to a meta-management approach for the design analysis. This approach was necessary because it is not about a special resource or a common good in particular, but about an approach that offers the possibility to be applicable for several resources. In order to ensure a better overview, all approaches were grouped together. A distinction was made between (a) a management concept, (b) a governance concept and (c) a more advanced approach. The difficulty in evaluating the individual meta-approaches and concepts was that there were sometimes hardly any uniform definitions, standards or framework conditions for the respective concepts/approaches. Depending on the application, the 


\section{Alexa K. Lutzenberger et al.}

author's view and the inclusion of different tools and methods or combinations of approaches, the concepts can take more or less social-ecological aspects into account and vary in their design, criteria and principles. Taking into account the divergences, an attempt was made to filter out the generally valid criteria of a concept/approach and to evaluate only these on the basis of the design principles. In addition, approaches are summarised which are to be treated synonymously, such as 'co-management' which is also referred to in the literature as joint-management, collaborative management or cooperative management and so on. In the second step, a literature analysis on the topic of design principles was methodically carried out. In the selection process, only design criteria related to $\mathrm{CPR} / \mathrm{CG}$ will be considered. In addition, the principles cover as broad an interdisciplinary field as possible. Social, ecological, economic and cultural aspects should be taken into account in as balanced a compilation as possible and take account of the sustainability concept.

In total, the evaluated portfolio - according to in-depth literature analysis comprises 59 design principles and criteria that promote sustainable and collective use of natural resources. Each principle includes a brief description, which facilitates the subsequent assessment of the respective management approach. In a further step, those principles were extracted which allow an assessment of the management at the macro level. For this purpose, 22 design principles are selected and assigned to a respective major category. The matrix, therefore, includes the following main categories and their design principles:

\section{Fairness and legitimacy}

- Collective choice arrangements.

- Most individuals affected by the operational rules can participate in modifying the operational rules (Anderies et al. 2004; Bruns 2008; Cox et al. 2010; Ostrom 1990).

- Graduated sanctions.

- Appropriators who violate operational rules are likely to be assessed graduated sanctions (depending on the seriousness and the context of the offence) by other appropriators, by officials accountable to the appropriators, or by both (Anderies et al. 2004; Bruns 2008; Cox et al. 2010; Ostrom 1990).

- Clear allocation and ownership of rights and obligations (Araral 2013).

- Fairness in the allocation of risks, costs and benefits (Araral 2013).

- Resources and equity (Gruber 2010).

- Environmental justice is a social imperative that includes recognising local values.

- Seek to improve (or minimise negative effects upon) the local economy. 
- Recognise the need for linkages between conservation and local economy based upon equity, local needs, financial and environmental sustainability.

- Seek equitable and fair distribution of local benefits, potentially including compensation for protecting natural resources.

- Regulated access to natural resources and graduated sanctions can help ensure equity.

II Collaboration

- Networks/collaborative partnerships (Gruber 2010; Pomeroy et al. 1998).

- Is the bringing together of information and expertise.

- Networks may take many forms: alliances of support groups, organisations of stakeholders, and federations of resource users.

- They may be formal or informal.

- Networking is closely associated with the establishment of four types of linkages: (1) with other communities and projects involved in similar initiatives; (2) with sources of power and influence; (3) with NGOs and business groups, and (4) with donors and government agencies.

- Networks and partnerships are integral to building social capital and serve as a catalyst synchronise finding innovative strategies and solutions.

- Collaborative partnerships are vital to leveraging resources and supporting implementation.

- Stakeholder training, workshops, and other collaborative learning opportunities can build social capital and commitment.

- Seek agreement among key environmental NGOs, governments, and private sector to work collaboratively and to share resource and responsibilities.

- Ownership by community members and other stakeholders enhances design, implementation, and operation, support cohesion, and encourages long-term commitment.

- Coordination between government and community (Pomeroy et al. 1998).

- A coordinating body is established, external to the local group or organisation and with representation from the group or organisation and government, to monitor the local management arrangements, resolve conflicts, and reinforce local rule enforcement.

- Participatory decision making (Gruber 2010).

- Effective participatory problem solving and decision making is enabled by a well- structured and facilitated dialogue involving 
scientists, policy makers, resource users, practitioners, and community members.

- Decision making is informed by analysis of key information about environmental and human-environmental systems including life aspirations of local people.

- It is vital to create a shared holistic vision/plan that anticipates probable environmental, social, and economic outcomes.

- The policy creation process should include a wide range of key expert and non-expert constituency/community groups at the table.

- Participatory problem solving should provide opportunities for the sharing of knowledge and collaborative learning about socialecological systems.

III Information

- Interdisciplinary.

- Management must be based on the realm of scientific studies and thereby include all disciplines (Fowler 2003).

- Communication and Information Dissemination (Gruber 2010).

- Well-designed communication systems provide information sharing that support multiple social networks and raises the level of knowledge and awareness.

- $\quad$ Linkages are provided between different information and knowledge systems to support learning, decision making, and change.

- $\quad$ Effective communication supports openness and transparency.

- Promote information sharing between experts and non-experts through multiple approaches including seminars and workshops; printed, electronic, and mass media; and projects.

- Explicitly state expectations and limits.

- Information based (Fowler 2003).

- Management must be based upon information, including the products of scientific research, monitoring, and assessment.

- Research and information development (Gruber 2010).

- There is a common information base that is accessible and useful.

- Decisions should be based upon a broad but systematic body of information.

- Integrated information includes technical, scientific, social, quality-of-life, economic, and other forms of local knowledge, including indigenous experiential knowledge.

- An economic evaluation of environmental assets is a valuable information base. 
- On-going research is necessary to improve upon existing solutions including a role for community members in the collection of scientific information.

IV Security

- $\quad$ Risk averse.

- Management must be precautionary and avoid risk in achieving sustainability.

- Addressing poverty and reducing inequities (Bunch et al. 2011).

- Promoting resilience (health, ecosystem function, biodiversity) (Bunch et al. 2011).

- 'resilience' as an integrating concept that bridges health and sustainability concerns across scales from individuals to communities and ecosystems.

- $\quad$ Reduce vulnerability against natural hazards.

- $\quad$ Security of rights (Lindsay 1998).

- There must be a certainty that the rights cannot be taken away or changed unilaterally and unfairly.

- The rights must be clear.

- There must be certainty about the subjects of the rights.

- The government entity entering into the agreement must have clear authority to do so.

- Conflict management and resolution (Gruber 2010).

- Difficult realities and conflicts are inherent in community-based social-ecological systems.

- Plan for and develop capacity and strategies for conflict management and resolution at the time of initiation of a community-based social-ecological initiative.

- Recognise the central role of institutions outside of the Community-Based organisation in mediation of environmentsociety conflicts.

- Work to transcend organisational rivalry and competition between organisations or stakeholder groups.

- Design participatory decision making processes that promote dialogue and reduce factionalism.

\section{$\mathrm{V}$ Adaptiveness}

- $\quad$ Adaptive leadership and co-management (Gruber 2010).

- A robust social-ecological organisation is designed and supported to be a learning organisation that supports adaptive capacity.

- A learning organisation and an optimum management system are 
resilient to perturbation, with an ability to cope with external shocks and rapid change.

- Adaptive co-management and adaptive leadership are dynamic and focused on processes rather than static structures.

- Adaptive co-management approaches include roles for local government, local community members, NGOs, and private institutions and decision making inclusive of people affected by and knowledgeable of the issues.

- An effective co-management approach engages, trains, and mobilises community member in the work of the organisation.

VI Polycentricity

- Devolution and empowerment (Gruber 2010).

- True sharing of power and responsibility (devolution of authority and responsibility) between government authorities, community groups, and the broader community with enhanced local decision making improve outcomes.

- Most individuals affected by environmental rules and regulations, including those who are often marginalised, should be included or represented in the group who make or modify the rules.

- There are nested, multiple layers of governments and enterprises related to role/activities of decision making, appropriation, monitoring, enforcement, conflict resolution, and governance.

- Devolution of control and decision-making significantly changes the relationship between central governments and rural/regional areas and if done effectively, can engage and build the commitment of local community members.

- Establishing clear rules, procedures, and regulations can empower the local community.

- $\quad$ Nested enterprises (Anderies et al. 2004; Bruns 2008; Cox et al. 2010; Ostrom 1990).

- Appropriation, provision, monitoring, enforcement, conflict resolution, and governance activities are organised in multiple layers of nested enterprises.

VII Transparency

- Monitoring the resource (Anderies et al. 2004; Bruns 2008; Cox et al. 2010; Stern 2011; Ostrom 1990).

- Monitors who are accountable to the users monitor the condition of the resource.

- $\quad$ Establish independent monitoring of the resource and its use that is accountable to the range of interested and affected parties. 
- $\quad$ Public trust and legitimacy/confidence building measures (Gruber 2010).

- Work must be viewed by the community as legitimate to build community trust.

- Local leaders are integral to efforts in establishing trust and credibility.

- Support by local elected officials will build trust and legitimacy.

- Participatory approaches to problem-solving and decision making are critical to building legitimacy.

- Transparency in activities, including decision making, supports the building of trust.

Figure 18.2 shows with respect to natural resources as commons the effect of the design principles and management approaches on the one hand and the social cohesion of the community on the other.

Furthermore, the analysis makes it clear that the management approaches available to us create the possibilities to manage a resource collectively from Commons points of view and that it is not necessarily new management concepts required but the existing is able to promote these possibilities. Aspects such as polycentric/decentralisation and co-management, which lie in the broad midfield, show that links on the horizontal as well as vertical scale and level (bridging, linking) do not yet experience sufficient implementation/ application in concepts and can be supplemented here by suitable combinations with other management approaches, which have their focus there. Integration potential exists particularly in the implementation on a structural level. The same applies to sanction, poverty or conflict resolution mechanisms in connection with securing rights.

Many of the listed approaches and concepts of the matrix can be freely combined. Some of the possible combinations of individual approaches that can

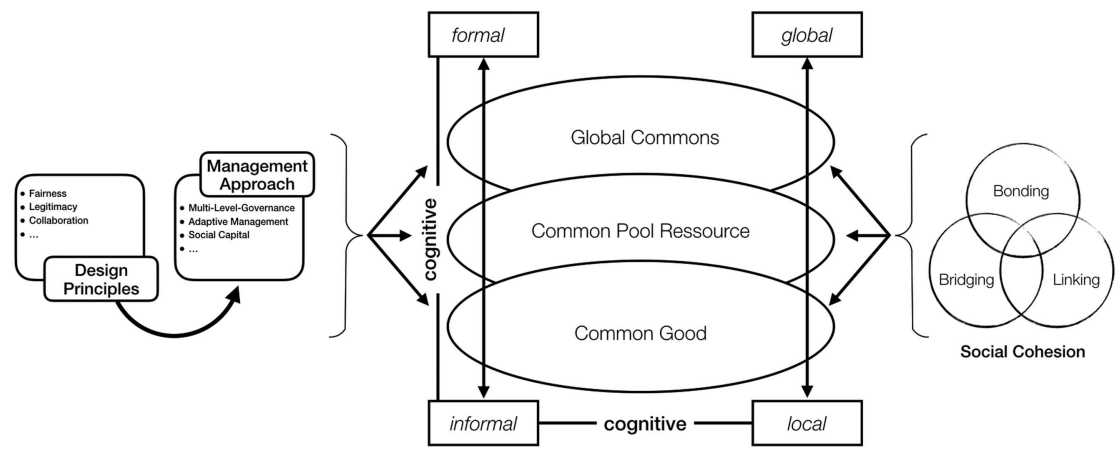

Figure 18.2 The relationship between social cohesion and the management of commons. Source: Lutzenberger, Lichter and Holzgreve (2015). 
very often be found in the Commons-Literature are already pointed out and evaluated in the matrix. For example, Adaptive Collaborative Management, which is made up of the individual approaches of Adaptive and Collaborative Management. Consequently, the matrix focuses on individual approaches, since potential combinations cannot be mapped and evaluated in their entirety in the matrix due to the multitude of possible combinations. However, the matrix can be understood as a tool which enables combinations. On the basis of the matrix it is possible for the observer to read off the evaluation of the individual approach accordingly and to carry out combinations independently. Combinations of individual approaches offer the option to combine and promote different strengths of the respective concepts and to sensibly reduce weaknesses by adding further approaches. This procedure can be carried out theoretically and practically during and before a project phase according to the problem situation and planning.

The listed design principles are thus a guide for the implementation of the commoning process (from weak to strong) as well as for commons research and projects. The design principles are not a methodical checklist per se, and their consideration is not a guarantee for the success of the respective project. However, the inclusion of the design principles can significantly influence the structuring of the process and help to control, inform, and shape the commoning process. Therefore, the design principles are elements of a more effective research process, which supports and applies knowledge generation in order to solve problems or to recognise them in advance. The design principles in the context of the listed management approaches contribute more to the joint management of natural resources, which support the restoration and conservation of ecosystem services and ensure their sustainable use. In addition, synergies and interrelations are created with important international environmental agreements, guidelines and requirements such as Agenda 21, the Millennium Development Goals, or the CBD, to name but a few of them, which, with their principles and framework conditions, also call for the joint and equitable conservation of natural resources.

As already described in the definition chapter, global resources are freely accessible for everyone, can be used without restriction, and thus belong to everyone. There is no direct form of ownership/order which assigns the resource to a person, a state or an organisation, among others, and which regulates it. The difficulty in controlling global resources lies in the lack of property rights. There is still the question who decides about global resources and their legitimateness. These and other questions remain in the scientific discourse by permanent degradation progresses. There is agreement that Antarctica, the oceans, space and the atmosphere are now recognised as global commons. The used definition, however, includes far more resources such as biodiversity, rare earths, genetic resources, etc.

The consequences of the lack of property rights are persistent overexploitation, pollution and lack of responsible use of resources and services, named in literature as the tragedy of the commons. A further difficulty lies in the limits of global commons, which must first be defined by the respective community. This 
appears more difficult, especially for topics such as biodiversity, seas, and so one. Different interests, risks, finances, property claims, forms of government meet and have to be decided at the highest level in order to be negotiated in the interest of all humanity. Especially the global commons as part of the common pool resources and integrated into an ecological cause-and-effect structure experience severe degradation and waste due to a lack of international regulation and control mechanisms. In this way, seas become no-man's-land and rainforests become bioenergy producers. The consequences of the lack of control and the lack of access to resources as a global common good are directly felt by the world's population. Issues such as the scarcity of drinking water, food security, climate change and energy supply have long been associated with the lack of regulation of global commons. The time scales and the current status of the existing degradation are also problematic. For example, the gases emitted during climate change such as carbon dioxide, methane, and others are globally distributed in the atmosphere for centuries, the extinction of species is irreversible, if a finite resource has been degraded, it will no longer renew itself, etc., which also puts intra- and intergenerational justice even more in the focus. In addition, scientific statements on climate change, biodiversity are subject to rather rough estimates based on scenario analyses, and others, which are partly based on a lack of data and monitoring. The overarching complexity of these systems and their interaction make an accurate analysis and prediction of system changes difficult. The same applies to technologies whose extent and effect cannot be estimated (for example geoengineering) (Stern 2011).

Consequently, there are gaps in communication and information dissemination as well as in the research of global commons as a whole. The consequential and risk costs of the use and overexploitation of global resources have so far been carried by all, e.g. the effects of climate change such as rising sea levels or the increase in periods of drought. The danger of competition for the last global resources, the individual exploitation of economic benefits culminates in collective damage. The individual's concern about the global commons is nevertheless low. One way out of this dilemma would be to convert unrestricted access to a Community ownership regime. The resource would be managed jointly, rights and obligations defined, respected and monitored.

Today, the management challenge for natural resources lies in the fact that resources often do not belong to one state alone but have to be controlled beyond national borders (beyond national jurisdiction and legislation) and remain part of individual nations. This increases the complexity of the process of commoning. The social cohesion of countries must go beyond national boundaries, and all countries must be fundamentally united on management approaches, objectives, and institutions, otherwise the system will return to full access and be exposed to overexploitation. This procedure requires high reciprocity. A reciprocal giving and taking, because interests can collide and a common denominator must be found. Bromley and Cochrane named three possible forms for the control of the international 
policy of the commuter (facilitative, inducing, injunctive), whereby injunctive should be the latter option because it determines winners and losers in the process of the convention and leads rather to the exit from the alliance (Bromley \& Cochrane 1994).

The goal of international policy agreements should be, that all stakeholders see themselves through a common management in some way as winners and not as losers. Furthermore, the costs and benefits must be fairly shared. For an optimal international policy regime, the costs of leaking from the agreement would have to exceed the costs of accession (Bromley \& Cochrane 1994). Dealing with global commons thus implies, to a certain extent, a collaborative political approach (Multilateral political considerations include: (a) several states act jointly cooperatively and, in principle, equally, taking into account all interests; (b) the common interest is formally accredited in the form of contracts and agreed on arrangements that bind all parties involved (Cheneval 2011). Examples of multilateralism would be multilateral federations with common policies such as the European Union, or a multilateral environmental treaty such as the Kyoto Protocol). Opposed to multilateral action, varies states try to promote their own solutions in order to counter climate change and biodiversity loss. For a variety of reasons, states are less multilateral in environmental problems and are leaving risks of global change and cause-effect linkages unrelated. The 22 design principles and the management approaches can, however, provide initial help to analyse the process of control and to optimise it in relation to the design principles, thus positively advancing the commoning process. As a result, control attempts at a global level can be evaluated, compared, and improved, which is not yet the case. The application of the design principles to multilateral instruments thus contributes significantly to the management of global, national, regional, and local commons. The 22 design principles are applicable to all levels, although with growing complexity, increasingly challenging to implement.

\section{Case study: the water framework directive - an instrument for managing global water resources?}

The Water Framework Directive (WFD) was adopted by the European Parliament on 23 October 2000 with the aim of establishing a uniform regulatory framework for water policy within the EU. The Water Framework Directive is, therefore, an instrument for managing water pollution at the European level. Implementation takes place through the acceding countries, which results in a multitude of different management approaches for implementation. However, the analysis focus is primarily based on the content and framework of the WFD and less on the later implementation by the acceding countries. For this purpose, the application of the 22 design principles is examined in the establishment of a regulatory framework, namely on the Directive WFD 2000/60/EC. 


\section{Theoretical assumption of a commoning process}

If one assumes hypothetically that the first part of the commoning process took place, namely to form a community (social union, in this case, a multilateral state alliance), the second step would be to define the resource - in the concrete case of the WFD, it would be water (ground and surface water, river basins, etc.). For the regulation of the resource the European Union (EU) implemented the WFD as an institution. The WFD applies throughout Europe and controls all water bodies with the aim of improving the chemical and ecological condition. Through the multilateral agreement by the member states, one can assume that the EU treat the water bodies as a global common, although it is not named like that in the Directive. Thus the steps in the commoning process would be fulfilled from a theoretical point of view.

\section{Summary of the analysis}

The evaluation shows that the WFD has its strengths, especially in the categories of collaboration, information, transparency, and polycentricity. In the categories of fairness and safety, it is clearly below the requirements. The category adaptivity is, however, not included in the regulatory framework at all.

In the cross-section, it can be seen that the Directive has so far failed in its framework to take account of the local level of the accession countries and this is one of the most significant weaknesses in relation to the commoning process. Neither in the Directive nor the Common Implementation Strategy (CIS) - the joint implementation strategy of the WFD - could a reference be found to the local level. Consequently, the related design principles, such as collective choice arrangements or co-management are also negatively affected. Furthermore, it clearly appears, that addressing poverty and inequalities in the distribution of resources, costs, benefits, and risks is given little textual consideration, although poverty problems and conflicts with regard to water use are existent in the EU. Moreover, the issue of conflict management is also not pursued further by the WFD.

The WFD is a supranational institution and requires an implementation to the regional and local level. Due to the heterogeneity of the EU, the choice of management approaches is left to the acceding countries. In this way, they are given the flexibility to take into account their region-specific conditions. Thus the WFD does not exclude any approaches per se. However, exactly for this reason, the directive itself does not create any opportunities for collaborative management approaches. Furthermore, the regulatory framework does not provide an interrelation to the local economy, which is directly dependent on the water resources, and therefore does not create any linkage for the local community to see advantages in protecting the resources. Only in one section is an economic benefit for fisheries emphasised if the waters meet a certain quality standard: 'Protection of water status within river basins will provide economic benefits by contributing towards the protection of fish populations, 
including coastal fish populations (EC Directive 2000/60/EC 2010). Water users like agriculture, tourism and others more are not addressed. The inclusion of local resources - from a common good unit to resource pools - is addressed mainly from an ecological point of view but only partly from an economic and socio-cultural one. However, the current top-down mechanism of the WFD, that governs the entire water resource across Europe cannot mean the institutional decoupling of the local level in the regulatory framework. There is a strong link between the success of nature conservation and the co-participation of the local communities (Andrade \& Rhodes 2012). In the light of the current regulatory framework, the WFD can rather be located in a 'command and control' policy, which has to be modified under an assumed commoning process.

Furthermore, resilience as an approach and equitable distribution of risks, costs, and benefits are not addressed in the WFD. Fairness is also not a concept of the WFD. An adaptive concept approach in the regulatory framework could at least promote the cohesion between resilience and monitoring. Despite everything, when the 22 design principles were applied, the WFD achieved a $68 \%$ commoning rate. Assuming hypothetically that the implementation of the 22 design principles corresponds to a $100 \%$ commoning process, the consideration of all 22 design principles equates a 'strong commoning'. If, however, no or only a few design principles are taken into consideration, one can speak of a 'weak commoning'. Thus the WFD shows clear tendencies towards a rather strong commoning process.

Overall, the WFD thus achieved a considerable result. With the WFD, the EU as a multilateral alliance confers an approach to global common water on the European level. The trend towards a 'strong commoning' approach can be supported by the addition of complementary management approaches to the WFD framework. The analysed deficits show that a major problem is the lack of integration at the local level.

The optional approaches to improve the commoning process within the framework of the WFD are summarised as follows:

Category: Governance approach

- Adaptive governance

Category: Management approach

- Adaptive governance

Category: Complementary approaches

- Sustainable livelihood approach

- Collective action 
- Payments for ecosystem services

- Social capital

The combination of the chosen governance and management approaches covers $86 \%$ of the deficit design principles.

\section{References}

Anderies, J. M., M. A. Janssen, and E. Ostrom (2004). A Framework to Analyze the Robustness of Social-ecological Systems from an Institutional Perspective. Ecology and Society, 9. www.ecologyandsociety.org/vol9/iss1/art18/.

Andrade, G. S. M., and J. R. Rhodes (2012). Protected Areas and Local Communities: An Inevitable Partnership toward Successful Conservation Strategies? Ecology and Society, 17.

Araral, E. (2013). A Transaction Cost Approach to Climate Adaptation: Insights from Coase, Ostrom and Williamson and Evidence from the 400-Year-Old zangjeras. Environmental Science \& Policy, 25, 147. DOI: 10.1016/j.envsci.2012.08.005.

Bleischwitz, R., et al. (2009). Ressourcenpolitik zur Gestaltung der Rahmenbedingungen: Paper $z u$ Arbeitspaket 3 des Projekts, Materialeffizienz und Ressourcenschonung' (MaRess) Endversion 2009., Wuppertal.

BMUB (2012). German Resource Efficiency Programme (ProgRess): Programme for the Sustainable Use and Conservation of Natural Resources, Berlin.

Bollier, D. (2014). The Commons as a Template for Transformation. Retrieved from https:// greattransition.org/publication/the-commons-as-a-template-for-transformation.

Bromley, D. W. and J. A. Cochrane (1994). Understanding the Global Commons, Madison, US.

Bruns, B. (2008). in Community-Based Water Law and Water Resource Management Reform in Developing Countries (Eds.: B. Koppen, M. Giordano, J. Butterworth), CABI.

Bunch, M. J., K. E. Morrison, M. W. Parkes, and H. D. Venema (2011). Promoting Health and Well-Being by Managing for Social-Ecological Resilience: the Potential of Integrating Ecohealth and Water Resources Management Approaches, Ecology and Society, 16. www.ecologyandsociety.org/vol16/iss1/art6/.

Butlin, J. (1989). Our Common Future. By World Commission on Environment and Development.' Journal of International Development vol.1 no.2 pp. 284-287. Available from: doi:10.1002/jid.3380010208 ISSN 1099-1328.

Cheneval, F. (2011). The Government of the Peoples: On the Idea and Principles of Multilateral Democracy, Palgrave Macmillan, New York.

Cox, M., G. Arnold, and S. Villamayor Tomás (2010). A Review of Design Principles for Community-based Natural Resource Management. Ecology and Society, 15.

de Moor, T. (2011). From Common Pastures to Global Commons: A Historical Perspective on Interdisciplinary Approaches to Commons, Nat. Sci. Soc. 19, 422.

European Community (EC) (2010). Directive 2000/60/EC of the European Parliament and of the Council of 23 October 2000. Establishing a Framework for Community Action in the Field of Water Policy.

Fowler, C. W. (2003). Tenets, Principles, and Criteria for Management:The Basis for Systemic Management. Marine Fisheries Review, 65(2).

Gordon, H. S. (1954). The Economic Theory of a Common-Property Resource: The Fishery, Journal of Political Economy, 62, 124. DOI: 10.1086/257497. 
Gruber, J. S. (2010). Key Principles of Community-Based Natural Resource Management: A Synthesis and Interpretation of Identified Effective Approaches for Managing the Commons, Environmental Management, 45, 52. DOI: 10.1007/s00267-008-9235-y.

Hardin, G. (1968). The Tragedy of the Commons, Science (New York), 162, 1243. DOI: 10. 1126/science.162.3859.1243.

Helfrich, S. (Ed.) (2012). Commons: Für eine neue Politik jenseits von Markt und Staat, Transcript-Verl., Bielefeld.

Hess, C. (2008). Mapping the New Commons: Presented at 'Governing Shared Resources: Connecting Local Experience to Global Challenges;' the 12th Biennial Conference of the International Association for the Study of the Commons, University of Gloucestershire, Cheltenham, England, 14-18 July, Cheltenham.

Holzgreve, S. (2015). Defining Natural Resources as Common Goods Bachelorthesis Lüneburg 2015.

Lindsay, J. M. (1998). Creating a Legal Framework for Community-Based Management: Principles and Dilemmas, Washington, DC.

Lutzenberger, A., and F. Lichter, S. Holzgreve (2015). Natürliche Ressourcen als Common Goods IntRess Arbeitspaket 6. Unpublished.

Mayntz, R. (2010). In Governance - Regieren in komplexen Regelsystemen: Eine Einführung (Ed.: A. Benz), VS Verl. für Sozialwiss. Wiesbaden, p. 65.

Ostrom, E. (1990). Governing the Commons: The Evolution of Institutions for Collective Action. The Political economy of institutions and decisions. Cambridge University Press, New York.

Ostrom, E. (1991). Governing the Commons: The Evolution of Institutions for Collective Action, Cambridge Univ. Press, Cambridge u.a.

Ostrom, E. (1996). Crossing the Great Divide: Coproduction, Synergy, and Development, World Development, 24, 1073.

Ostrom, E. (1999). Design Principles and Threats to Sustainable Organizations that Manage Commons. Retrieved from http://dlc.dlib.indiana.edu/dlc/handle/10535/5465. Workshop Working Paper W99-6.

Ostrom, E. (2008). Design Principles of Robust Property -Rights Institutions: What Have We Learned?, Lexington Books, Lanham.

Ott, K. and R. Döring (2004). Theorie und Praxis starker Nachhaltigkeit, Metropolis-Verl., Marburg.

Polski, M. M., and E. Ostrom (1999). An Institutional Framework for Policy Analysis and Design, Lexington Books, Lanham.

Pomeroy, R. S., B. M. Katon, and I. Harkes (1998). Fisheries Co-management: Key Conditions and Principles Drawn from Asian Experiences.

Quilligan, J. (2014). In Commons: Für eine neue Politik jenseits von Markt und Staat (Ed.: S. Helfrich), Transcript-Verl. Bielefeld, p. 99.

Reid, W. V. (2005). Ecosystems and Human Well-being: Synthesis: A Report of the Millennium Ecosystem Assessment, Island Press, Washington, DC.

Reller, A., L. Marschall, S. Meissner, and C. Schmidt (2014). Ressourcenstrategien: Eine Einführung in den nachhaltigen Umgang mit Ressourcen, WBG - Wissenschaftliche Buchgesellschaft, Darmstadt.

Schütz, H. and S. Bringezu (2008). Resource Consumption of Germany - Indicators and Definitions, Dessau-Roßlau.

Söllner, A. (2014). Globalization, Greed, and Exploitation. How to Break the Baleful Path?, Journal of Business Economics, 84, 1211. 
Stern, P. C. (2011). Design Principles for Global Commons: Natural Resources and Emerging Technologies, International Journal of the Commons, 5, 213.

UNEP (2012). Responsible Resource Management for a Sustainable World: Findings from the International Resource Panel.

Vanni, B. (2014). Understanding the Commons: The Reception of Elinor Ostrom's work in Italian Scholarship, Law, and Jurisprudence. Bloomington, IN: Paper presented at Colloquium at the Workshop in Political Theory and Policy Analysis. http://hdl.handle.net/ 10535/9364.

Zell, H. (2011). Die Grundlagen der Organisation: Lernen und Lehren: Mit Multiple-ChoiceAufgaben, Books on Demand, Norderstedt. 